\title{
Mixing layer height retrievals by multichannel microwave radiometer observations
}

\author{
D. Cimini ${ }^{1,2}$, F. De Angelis ${ }^{2}$, J.-C. Dupont ${ }^{3}$, S. Pal ${ }^{4,5}$, and M. Haeffelin ${ }^{6}$ \\ ${ }^{1}$ IMAA-CNR, Potenza, Italy \\ ${ }^{2}$ CETEMPS, University of L'Aquila, L'Aquila, Italy \\ ${ }^{3}$ Institut Pierre-Simon Laplace, Université Versailles Saint Quentin, Guyancourt, France \\ ${ }^{4}$ Laboratoire de Météorologie Dynamique (LMD), CNRS-Ecole Polytechnique, Palaiseau, France \\ ${ }^{5}$ Department of Environmental Sciences, University of Virginia, Charlottesville, VA, USA \\ ${ }^{6}$ Institut Pierre-Simon Laplace, Centre National de la Recherche Scientifique, Ecole Polytechnique, Palaiseau, France
}

Correspondence to: D. Cimini (domenico.cimini@imaa.cnr.it)

Received: 22 April 2013 - Published in Atmos. Meas. Tech. Discuss.: 5 June 2013

Revised: 29 August 2013 - Accepted: 1 October 2013 - Published: 1 November 2013

\begin{abstract}
The mixing layer height (MLH) is a key parameter for boundary layer studies, including meteorology, air quality, and climate. MLH estimates are inferred from in situ radiosonde measurements or remote sensing observations from instruments like lidar, wind profiling radar, or sodar. Methods used to estimate MLH from radiosonde profiles are also used with atmospheric temperature and humidity profiles retrieved by microwave radiometers (MWR). This paper proposes an alternative approach to estimate MLH from MWR data, based on direct observations (brightness temperatures, $\mathrm{Tb}$ ) instead of retrieved profiles. To our knowledge, MLH estimates directly from $\mathrm{Tb}$ observations have never been attempted before. The method consists of a multivariate linear regression trained with an a priori set of collocated MWR Tb observations (multifrequency and multi-angle) and MLH estimates from a state-of-the-art lidar system. The proposed method was applied to a 7-month data set collected at a typical midlatitude site. Results show that the method is able to follow both the diurnal cycle and the day-to-day variability as suggested by the lidar measurements, and also it can detect low MLH values that are below the full overlap limit $(\sim 200 \mathrm{~m})$ of the lidar system used. Statistics of the comparison between MWR- and reference lidar-based MLH retrievals show mean difference within $10 \mathrm{~m}$, root mean square within $340 \mathrm{~m}$, and correlation coefficient higher than 0.77 . Monthly mean analysis for daytime MLH from MWR, lidar, and radiosonde shows consistent seasonal variability, peaking at $\sim 1200-1400 \mathrm{~m}$ in June and decreasing down to
\end{abstract}

$\sim 600 \mathrm{~m}$ in October. Conversely, nighttime monthly mean MLH from all methods are within $300-500 \mathrm{~m}$ without any significant seasonal variability. The proposed method provides results that are more consistent with radiosonde estimates than MLH estimates from MWR-retrieved profiles. MLH monthly mean values agree well within 1 standard deviation with the bulk Richardson number method applied at radiosonde profiles at 11:00 and 23:00 UTC. The method described herewith operates continuously and is expected to work with analogous performances for the entire diurnal cycle, except during considerable precipitation, demonstrating new potential for atmospheric observation by ground-based microwave radiometry.

\section{Introduction}

The atmosphere boundary layer is characterized by turbulent fluctuations that induce mixing of aerosol particles and other trace gases and govern vertical distribution of thermodynamic variables. During daytime the lower layers tend to be unstable as a result of surface heating, and the boundary layer tends to be neutrally stratified due to the thermally driven convection. At night a shallow stable layer forms near the surface in which mixing occurs primarily through intermittent turbulence, leaving a residual layer above (Stull, 1988). The mixing layer height (MLH) defines the top of the layer near the surface where mixing is occurring. The MLH 
is a key parameter for boundary layer applications, including meteorology, weather prediction, air quality, and even climate (Deardorff, 1972; Stull, 1988; Garratt, 1992; Piringer et al., 2007; Pal et al., 2012). For instance, the determination of the MLH is crucial to study exchanges between the surface and the atmosphere. In fact, the way pollutants disperse in the atmosphere largely depends on how the MLH has developed: an unstable convective layer favors the dilution of pollutants, while a shallow stable layer favors their trapping near the ground. Here, we adopt the MLH definition of Seibert et al. (2000), as "the height of the layer adjacent to the ground over which pollutants emitted within this layer or entrained into it become vertically dispersed by convection or mechanical turbulence". This definition applies both for daytime, where the MLH is the top of a well-mixed layer, and for nighttime, where the MLH is the top of the stable layer in which surface-emitted pollutants are mixed through intermittent turbulence.

The mixing layer height can be associated to features in the vertical gradients of atmospheric constituents or thermodynamical structure. The vertical information may be obtained either with in situ measurements such as radiosondes or with ground-based observations from remote sensing instruments like light detection and ranging (lidar), sonic detection and ranging (sodar), or wind profiling radar. For example, several approaches have been reported to date to estimate MLH using wind profiler radar signal (Bianco and Wilczak, 2002; Bianco et al., 2008), lidar backscatter signal (Baars et al., 2008), or sodar echo (Beyrich, 1995). A quite comprehensive review of methods for the operational determination of the mixing height is given by Seibert et al. (2000), in which these methods are compared, and strengths and limitations of each method are discussed. For example, MLH is often estimated from the detection of the sharp gradient in the lidar backscatter signal due to aerosol decay at the top of the mixing layer. However, the lidar transceiver overlap factor causes an offset in the measures of the MLH because stratifications below a certain height, the so-called overlap height, cannot be detected (Haeffelin et al., 2012), and nor can the nocturnal stable boundary layer depth, which is often below that height. In recent years, new algorithms have been developed for estimating MLH (Pal et al., 2010; Wang et al., 2012; Granados-Muñoz et al., 2012), though the automatic detection of the top of the mixing layer still remains challenging, especially during shallow stable or nocturnal boundary layer when the mixing layer is not well defined. Surface diagnostic methods are used as a proxy for the depth of the stable boundary layer (Schmid and Niyogi, 2012). However, traditional methods were found to perform poorly (Vickers and Mahrt, 2004), and new formulations are continuously proposed to improve the performances (Steeneveld et al., 2007).

Thus, a synergy between different techniques, based on different aspects of the boundary layer, may be explored to improve the MLH estimate around the clock during all meteorological conditions (Praz, 2013). In this perspective, microwave radiometer (MWR) observations can provide a valuable contribution to the determination of the MLH, providing estimates of temperature and humidity in the lower troposphere. Temperature and humidity profiles retrieved by MWR can be used to feed tools developed for estimating MLH from radiosonde temperature and humidity profiles (Seidel et al., 2010), as for example the "parcel method" (Holzworth, 1964; Seibert et al., 2000), and thus providing an independent source of MLH estimates (Wang et al., 2012; Granados-Muñoz et al., 2012; Praz, 2013). In this paper, we present yet another approach based on MWR, where MLH is not inferred from the MWR-retrieved temperature and humidity profiles, but instead estimated directly from MWR observations, i.e. brightness temperatures (Tb). Thus, this approach is independent of the MWR profile retrievals and is based entirely on the MWR direct observations, Tb. The physical basis of the proposed approach is that the observed $\mathrm{Tb}$ carry mixed information on temperature, humidity, and virtual potential temperature profiles. Features in the vertical gradient of these profiles may be associated to MLH. Thus, the information content of $\mathrm{Tb}$ is exploited in a statistical sense to estimate the scalar variable MLH. The method is calibrated to the lidar in the sense that it trains the MWR retrieval to identify structures in the Tb that are most consistent with the MLH definition above. The proposed approach brings up new potential for MWR observations, as to our knowledge MLH estimates directly from Tb observations have never been attempted before. The paper is organized as follows: Sect. 2 presents the data set we used for this analysis; Sect. 3 presents the details of the methodology and the proposed retrieval algorithm; Sect. 4 discusses the results and the validation; Sect. 5 summarizes the findings and draws the final conclusions.

\section{Data set}

The data set considered here was collected at the Site Instrumental de Recherche par Télédétection Atmosphérique (SIRTA), a French national atmospheric observatory dedicated to cloud and aerosol research (Haeffelin et al., 2005). SIRTA is located at Palaiseau ( $48.8^{\circ} \mathrm{N}, 2.36^{\circ} \mathrm{E}, 65 \mathrm{~m}$ a.s.l.), $20 \mathrm{~km}$ south of Paris (France) in a semi-urban environment on a $10 \mathrm{~km}$ plateau. Active and passive remote sensing instrumentations are routinely operated at SIRTA, including a multichannel MWR, a backscatter lidar, and a sonic anemometer, while operational radiosondes are launched twice a day by Météo-France (the French national weather service) from Trappes, $12 \mathrm{~km}$ West of SIRTA. The availability of all these nearly colocated instruments allows us to demonstrate the proposed technique. A data set spanning over more than six months (March-October 2011) is utilized here. 


\subsection{Radiosonde data}

The radiosondes used for the analyses presented are M2K2 and M10 sondes manufactured by MODEM, providing profiles of pressure, temperature, relative humidity, dew point temperature, and horizontal wind at $2 \mathrm{~s}$ resolution. Though infrequently (few times per day), radiosoundings remain the de facto standard for upper air monitoring and provide the most accurate information on the vertical structure of the troposphere and lower stratosphere. Two radiosondes per day are launched at 11:00 and 23:00 UTC from the Météo-France site in Trappes. A total of 424 radiosondes in the period from March to October 2011 are available for this analysis. The MLH can be inferred from radiosonde profiles with a variety of methods (Seibert et al., 2000; Seidel et al., 2010). In this paper, we compute two MLH estimates for each radiosonde, using the following methods:

- the thermodynamical (PTU) method (relying on temperature and humidity profiles only); this is a combination of the parcel method, for estimating MLH in convective boundary layer, and of the surface-based temperature inversion and the virtual potential temperature gradient methods, for estimating MLH during nocturnal and stable boundary layer.

- the bulk Richardson number (Rbn) method (relying on temperature, humidity, and horizontal wind profiles); this evaluates the ratio of convectively produced turbulence divided by turbulence generated by wind shear against a critical value.

According to the literature, threshold for the bulk Richardson number is generally set between 0.10 and 0.40 (Sørensen et al., 1996). For example, the value 0.25 is used to estimate the boundary layer height provided in the ERA-Interim data (von Engeln and Teixeira, 2013). Here we set it to 0.22 or 0.33 for day and night radiosondes, respectively, for unstable (Vogelenzang and Holtslag, 1996) and stable (Wetzel, 1982) conditions. However, it shall be noted that the value of the threshold has modest impact on the estimated MLH. In fact, our results change only slightly (27 m mean difference) if we fix the threshold to 0.21 (Menut et al., 1999) as adopted by Haeffelin et al. (2012). Although the Rbn method is expected to be more reliable, as it also exploits the information on wind shear, the PTU method is more flexible as it can be applied to standard PTU radiosonde with no wind measurement. For further details on the above methods, see Seibert et al. (2000) and Seidel et al. (2010) and references therein.

\subsection{MWR data}

The multichannel MWR deployed at SIRTA is a humidity and temperature microwave profiler (HATPRO) manufactured by Radiometer Physics GmbH (Germany) (Rose et al., 2005). It measures $\mathrm{Tb}$ at 14 channels $(22.24,23.04$,
23.84, 25.44, 26.24, 27.84, 31.4, 51.26, 52.28, 53.86, 54.94, $56.66,57.3,58.0 \mathrm{GHz})$ and 7 elevation angles $(90,42,30$, $\left.19,10,5,0^{\circ}\right)$. Tb are calibrated using a combination of noise diode injection and a reference target at ambient temperature. The noise diode effective temperature is determined by observing an external cryogenic target less frequently (three to six months). Typical Tb noise level is within $0.5 \mathrm{~K}$. However, systematic differences with respect to radiosonde-based simulations may account for several degrees (Löhnert and Maier, 2012). Atmospheric temperature and humidity profiles, as well as column-integrated water vapor (IWV) and liquid water path (LWP), can be retrieved from MWR observations using a variety of inversion methods, including multivariate regression, neural networks, and variational approaches (Solheim et al., 1998; Cimini et al., 2006, 2009). The HATPRO proprietary software provides linear regression, quadratic regression, as well as neural networks (Rose and Czekala, 2010). The HATPRO at SIRTA was set to use the neural networks method, which is trained with thousands of profiles generated from historical data sets of operational radiosondes. Ten years of radiosonde data launched from Trappes were used for the training of the SIRTA HATPRO. The information content of MWR observations on the vertical distribution of atmospheric thermodynamical variables resides in the differential absorption of multifrequency and multi-angle $\mathrm{Tb}$ observations. Note that multi-angle observations sample different volumes with respect to zenith observations. However, these observations carry additional information on thermodynamical vertical profiles (Westwater, 1993; Löhnert et al., 2009), especially when the horizontal homogeneity assumption holds. MWR observations inherently present significant redundancy, leaving just a few independent pieces of information about the vertical thermodynamical structure. For temperature profiles most of the information content and the vertical resolution resides in the first $2 \mathrm{~km}$, while for humidity profiles the information is spread along the vertical range but at coarser resolution. For a generic MWR operating in the $20-60 \mathrm{GHz}$ range, Löhnert et al. (2009) showed that the degrees of freedom for signal (DFS), i.e. the number of independent levels that can be retrieved, are as follows: (i) for temperature profiles, DFS depend only slightly on atmospheric conditions, but range from $\sim 2$ to 4 , respectively, for zenith and multi-angle observations; (ii) for humidity profiles, DFS are almost independent on elevation angles, but depend noticeably on the water vapor content (DFS $\sim 1-3$ from dry to humid environment). An example of $24 \mathrm{~h}$ time series of temperature, water vapor mixing ratio, and virtual potential temperature profiles derived from MWR data is shown in Fig. 1. The temperature shows a clear diurnal variation, with the solar radiation warming up the boundary layer from around 07:00 UTC (09:00 local time) until 19:00 UTC, and the development of a weak inversion layer during the night hours (03:00 to 05:00 UTC). As a consequence, the potential temperature transits from stratified conditions to a well-developed mixing within the convective 

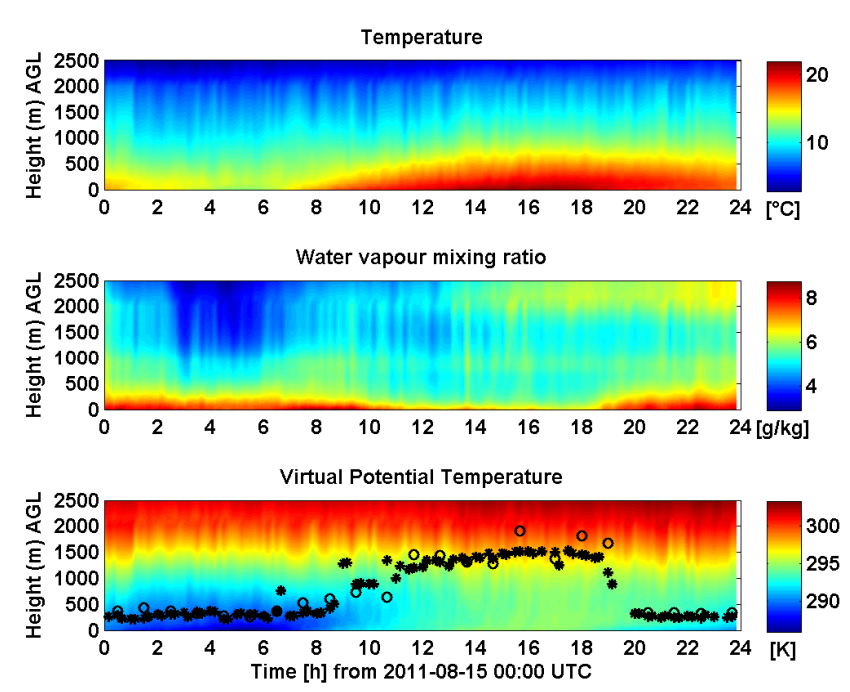

Fig. 1. $24 \mathrm{~h}$ time-height cross section of (top) temperature, (middle) water vapor mixing ratio, and (bottom) virtual potential temperature as derived from HATPRO MWR data collected at SIRTA on $15 \mathrm{Au}-$ gust 2011. Black stars and circles indicate the MLH estimates from lidar and MWR data, respectively, as discussed in Sect. 3.

boundary layer. MWR observations ( $\mathrm{Tb}$ ) and products (IWV, LWP, temperature and humidity profiles) are available at $\sim 1$ min temporal resolution. Currently, a direct estimate of the MLH is not provided by HATPRO (Rose and Czekala, 2010), nor by any other commercial MWR.

\subsection{Lidar data}

The lidar deployed at SIRTA is a $355 \mathrm{~nm}$ ALS450 backscatter lidar developed by Leosphere (France) (Lolli et al., 2011). Raw lidar data are available at $30 \mathrm{~s}$ and $15 \mathrm{~m}$ temporal and vertical resolutions, respectively. The MLH is derived from non-calibrated range corrected attenuated lidar backscatter profiles using the STRAT-2D algorithm that retrieves the most significant gradients in the profiles using two-dimensional gradient analyses as described in Haeffelin et al. (2012). The STRAT-2D algorithm provides 4 different layers for each $10 \mathrm{~min}$ period: the strongest gradient, the second-strongest gradient, the lowest-altitude gradient, and cloud-base height. However, the final attribution to determine which of these 4 retrievals best corresponds to the MLH remains ambiguous when using lidar data alone. The STRAT-2D algorithm has been recently upgraded with an enhanced attribution procedure that is fully explained in Pal et al. (2013). The attribution procedure is summarized here for clarity. Surface sonic anemometer measurements are used to compute heat fluxes and friction velocity. These parameters are then used to derive a Monin-Obukhov length and an atmospheric stability index. The times of early morning transition and early evening transition are determined from stability transitions. A variance analysis is performed on the non-calibrated range corrected attenuated lidar backscatter

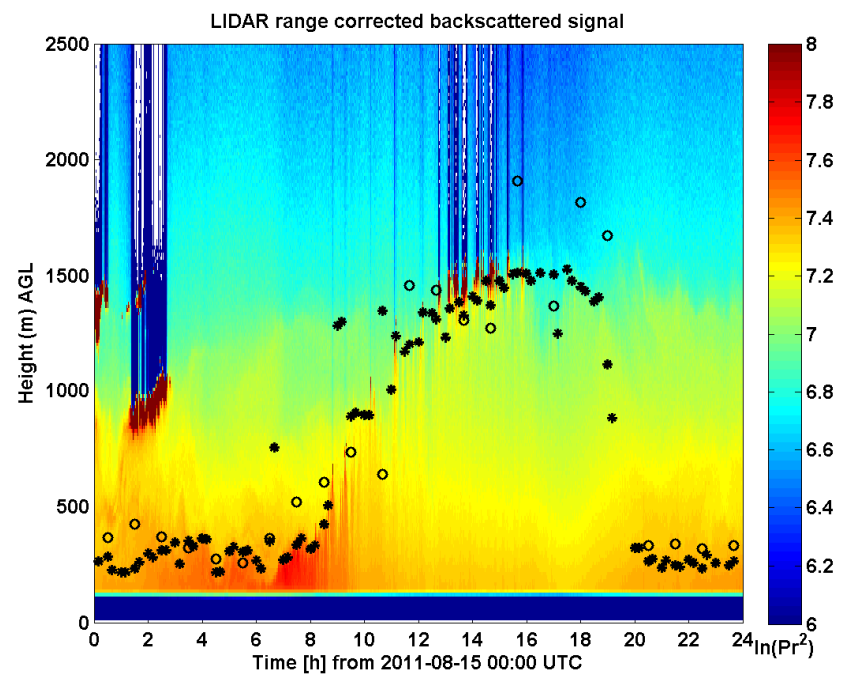

Fig. 2. $24 \mathrm{~h}$ time-height cross section of range corrected backscattered signal as measured by the ALS450 lidar at SIRTA on $15 \mathrm{Au}-$ gust 2011. Black stars and circles indicate the MLH estimates from lidar and MWR data, respectively, as discussed in Sect. 3.

profiles within each one-hour interval to determine the height of maximum variance. The vertical profile of variance is considered to provide a proxy of the vertical profile of turbulent mixing. The transition times and turbulence profiles are then used to determine the STRAT-2D-derived gradient that most likely traces the MLH (see Pal et al., 2013, for more details). The finally attributed MLH estimates are available at $\sim 10 \mathrm{~min}$ temporal resolution. An example of $24 \mathrm{~h}$ time series of range corrected backscatter profiles measured by the ASL450, as well as the associated MLH derived using STRAT-2D, is shown in Fig. 2. The diurnal cycle is such that the aerosols are concentrated in the lower levels during the nighttime stable boundary layer and then are dispersed into a progressively deeper layer as the convective boundary layer builds up. In the early evening transition period, when solar surface heating stops, a new shallow mixing layer develops near the surface.

Pal et al. (2013) compared MLH estimates derived from ALS450 observations and surface sonic anemometer measurements with MLH values obtained from radiosondes using the bulk Richardson number method (as described in Menut et al., 1999). The statistics they reported from 87 daytime and 81 nighttime measurements are given in Table 1 . Lidar anemometer and radiosonde MLH retrieval differences are found to be less than $150 \mathrm{~m}$ in $94 \%$ of daytime cases, and less than $50 \mathrm{~m}$ in $67 \%$ of nighttime cases.

\section{Methodology}

Temperature and humidity profiles retrieved by MWR every $\sim 1$ min may be used to feed the tools developed for inferring MLH from radiosonde temperature and humidity 
Table 1. Statistics for the comparison between MLH estimated from lidar and radiosonde observations (adapted from Pal et al., 2013). The number of radiosonde measurements used $(\mathrm{N})$, the height consistency interval considered $(\mathrm{H})$, the number of cases $(\%)$ where lidar and radiosonde MLH retrieval differences are less than $\mathrm{H}(\#)$, and correlation coefficient (CC) are reported.

\begin{tabular}{lrrrr}
\hline Period & $N$ & $H(\mathrm{~m})$ & $\#(\%)$ & $\mathrm{CC}$ \\
\hline Daytime & 87 & 150 & 94 & 0.97 \\
Nighttime & 81 & 50 & 67 & 0.93 \\
\hline
\end{tabular}

profiles (Seidel et al., 2010). However, as for radiosonde, the estimated MLH would depend on the different definition that is applied. In addition, the vertical resolution of MWR profiles is much lower than that provided by radiosondes, and the MLH estimate would be affected by that. Therefore, here we propose a different approach: a "direct" MLH estimate from Tb measurements. In fact, MLH can be estimated directly from $\mathrm{Tb}$ by investigating the covariance of these geophysical variables, provided that an independent "reference" observation for MLH is available for training. This approach offers the following advantages: (i) it is independent from uncorrelated retrieval errors in MWR temperature and humidity profiling, and (ii) it exploits all the DFS provided by the MWR observations for the retrieval of a scalar quantity, i.e. MLH. Despite these advantages, to our knowledge direct MLH estimates from Tb observations have never been attempted before.

Here we adopt a general notation to derive information on the atmospheric state vector $\boldsymbol{x}$ from the observation vector $\boldsymbol{y}$, which in our case represent MLH and Tb, respectively. The inverse problem $R$ of estimating $\boldsymbol{x}$ from $\boldsymbol{y}$, i.e. a finite number of highly correlated observations affected by measurement error $\varepsilon$, can be written as

$\hat{\boldsymbol{x}}=\mathbf{R}(\boldsymbol{y}+\boldsymbol{\varepsilon})$,

which represents an ill-posed problem and thus leads to nonunique solutions. In the case of an a priori data set of simultaneous state vectors $\boldsymbol{x}$ and observations $\boldsymbol{y}$ being available, it is possible to solve Eq. (1) through empirical regression. In the assumption of a moderate non-linear problem, the solution can be linearized by means of first-order Taylor expansion (calling $\boldsymbol{x}_{0}$ and $\boldsymbol{y}_{0}$ the mean state and observation vectors):

$\hat{\boldsymbol{x}}=\boldsymbol{x}_{0}+\mathbf{C}_{x y} \mathbf{C}_{y y}^{-1}\left(y-y_{0}\right)$

where $\mathbf{C}_{x y}$ and $\mathbf{C}_{y y}$ are extracted from the a priori data set and represent respectively the covariance matrix of the state vector $\boldsymbol{x}$ and the simultaneous observations $\boldsymbol{y}$, and the autocovariance matrix of $\boldsymbol{y}$. In our approach, the observation vector $\boldsymbol{y}$ consists of the HATPRO Tb measurements, while the state vector consists of MLH estimates, as derived for example from radiosonde or lidar data. We prefer the lidar because it provides a much larger data set (every $\sim 10 \mathrm{~min}$ ) covering the complete diurnal cycle, as opposite to twicedaily radiosondes. Therefore, we exploit the a priori data set of more than six months of colocated ALS450 lidar and HATPRO MWR data at SIRTA to train a multivariate regression as above. In particular, we define the following:

- The state vector $x$ : MLH (m) estimated by lidar backscattering with the upgraded STRAT2D algorithm (Pal et al., 2013).

- The observation vector $y$ : multichannel and multiangle $\mathrm{Tb}(\mathrm{K})$ measured by MWR at all 14 channels and 6 elevation angles $\left(90,42,30,19,10,5^{\circ}\right)$. Observations at $0^{\circ}$ elevation were not utilized to avoid antenna side-lobe ground contamination.

An initial sensitivity test was performed to choose the configuration of the observation vector. With respect ot the configuration above, other configurations have shown to increase the root-mean-square (RMS) error and decrease the correlation coefficient (CC) against the lidar reference. In particular, we found that excluding K-band channels (up to $30 \mathrm{GHz}$ ) leads to $7 \%$ RMS increase and $3 \% \mathrm{CC}$ decrease. Excluding cloud sensitive channels (up to $53 \mathrm{GHz}$ ) leads to $13 \%$ RMS increase and $5 \% \mathrm{CC}$ decrease. Excluding off zenith angles leads to $12 \%$ RMS increase and $4 \%$ CC decrease, though low elevations angles contribute only marginally $(\sim 1 \%)$. Thus, low elevation angles $\left(<19^{\circ}\right)$ could be avoided without a significant loss of information to make the method more robust against atmospheric inhomogeneity. Note that multiangle Tb observations sample different volumes with respect to lidar zenith observations. However, this is a common procedure in passive microwave sounding, which is meant to increase the information content on temperature profile by assuming horizontal homogeneity. Such an assumption is solid for opaque channels (i.e. $>53 \mathrm{GHz}$ ), though it depends on atmospheric conditions for transparent channels (especially in presence of broken clouds). Temporal colocation is obtained by averaging $\boldsymbol{x}$ and $\boldsymbol{y}$ in $10 \mathrm{~min}$ bins for the period May to October 2011, while only for March 2011 data are available in $5 \mathrm{~min}$ bins, due to intensive observations during a field campaign dedicated to fog investigation. The entire data set of 22287 colocations (2931 in March, 19356 in MayOctober) is divided into two independent sub-sets, one for training the regression coefficients while the other for testing the retrieval performances. Being a linear approach, we expect our method to be stable with respect to the dimensions of the training/test data sets. The training assumed STRAT2D MLH estimates as the reference "truth". The training was performed separately for each month to account for seasonal variations. Monthly or seasonal training is common for inversion techniques based on MWR data (Westwater et al., 1993), as it helps linearize the problem. Seasonal training could also have been adopted, which may turn out to be more robust for operational deployment at midlatitude sites. Moreover, 

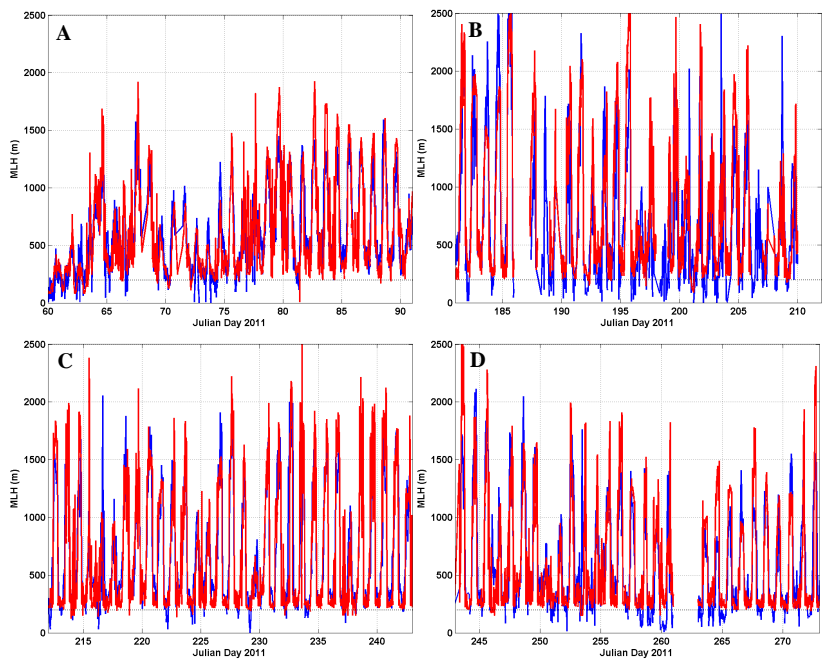

Fig. 3. Time series of MLH (in meters above ground level, a.g.l.) estimated from lidar backscatter (red line) and MWR Tb (blue line) observations. Time is expressed in Julian day (day of the year). The four panels indicate March (A), July (B), August (C), and September (D) 2011. The dashed lines at $200 \mathrm{~m}$ indicate the lidar full overlap height for the ALS450.

training is performed separately for night- and daytime, in order to separate convective and stable regimes. To separate night- and daytime periods, we choose the local time (LT) for monthly mean morning and evening transitions. These were estimated by the diurnal cycle of the stability index based on the near-surface micro-meteorological measurements of Obukhov length scale (see Pal et al., 2013). Thus, we adopted 11:00 LT as the time for mean morning transition and 19:00 LT for the mean evening transition in June, July, August and September, while 12:00 and 18:00 LT, respectively, for morning and evening transitions in March, May, and October. Therefore, 14 sets of coefficients ( 7 months times 2 day-night shifts) are determined, and the procedure picks alternatively each one to retrieve MLH from MWR Tb observations according to local date and time only. Since our regression approach is trained with actual measurements, $\mathrm{Tb}$ systematic and random errors are inherently accounted into the process, contributing to the overall performances described in the following section.

\section{Results}

Following the procedure described in Sect. 3, MLH are estimated from MWR Tb observations for the test set (i.e. not used for training) extracted from the entire data set spanning from March to October 2011. We tested the sensitivity of our method to the ratio of test / training data set dimensions and found results within $10 \%$ when inverting the ratio from $1 / 4$ to $4 / 1$. The results are presented in Fig. 3, together with the reference truth, i.e. the MLH estimated from lidar backscatter
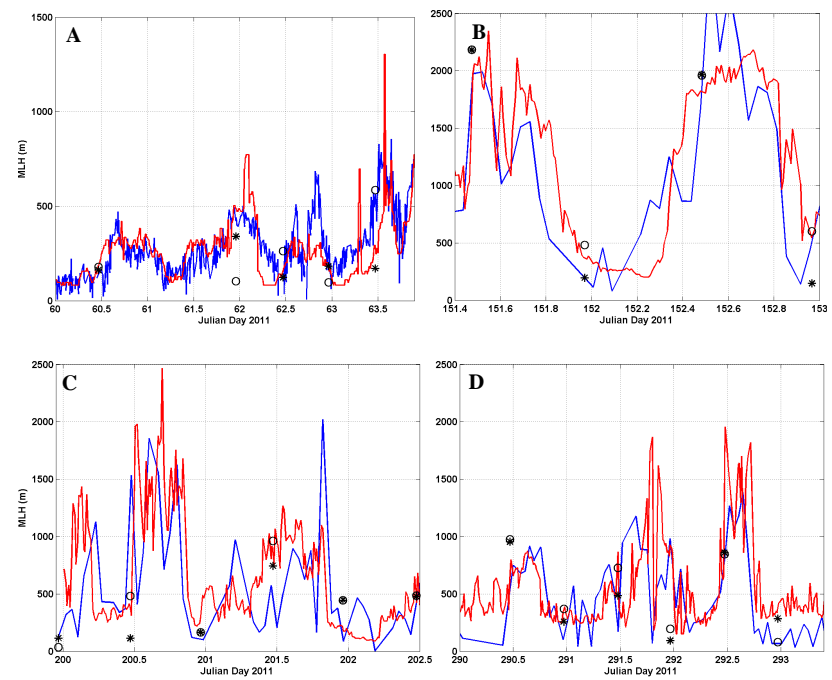

Fig. 4. Short time series of MLH (ma.g.l.) estimated from radiosonde profiles (black stars and circles indicating PTU and Rbn, respectively), lidar (red line) and MWR Tb (blue) observations. Panel A: [60.0-64.0] corresponds to [1 March 00:00 UTC-5 March 00:00 UTC]; Panel B: [151.4-153.0] corresponds to [31 May 09:36 UTC-2 June 00:00 UTC]; Panel C: [200.0-202.5] corresponds to [19 July 00:00 UTC-22 July 12:00 UTC]; Panels D: [290.0-293.5] corresponds to [17 October 00:00 UTC-20 October 12:00 UTC]

by the upgraded STRAT2D algorithm. Hereafter the altitude is expressed above ground level (a.g.l.). It is important to keep in mind that lidar and MWR rely on different aspects of the boundary layer to estimate MLH, the first being based on aerosol distribution while the second on thermodynamical properties. It is evident that the MWR-based MLH estimate is able to follow both the diurnal cycle and the day-by-day variability indicated by the lidar-based estimates. However, discrepancies are also evident, especially at low MLH values, where the MWR-based estimates go often lower than the corresponding lidar-based estimate. This behavior is consistent with the results in Wang et al. (2012), which conclude that lidar data under weak convection conditions reveal higher MLH values than those estimated from MWR profiles. Additionally, note that, due to the so-called lidar overlap limit, the lowest altitude of significant gradient detection is estimated at $\sim 200 \mathrm{~m}$ for the ALS450 (Royer et al., 2011; Haeffelin et al., 2012). However, lidar backscatter maximum can be detected in a region below the full overlap because the overlap function grows from 0 at the ground to 1 following an exponential function. Therefore detection below $200 \mathrm{~m}$ is possible at times (though only above $75 \mathrm{~m}$, as there is no overlap between the laser beam and telescope field of view below that (Lolli et al., 2008)), as can be seen in Fig. 3 during the first week of March. A way to go around the overlap limitation by sensor synergy for determining the entire diurnal cycle of MLH was exploited by Pal et al. (2012), using lidar 

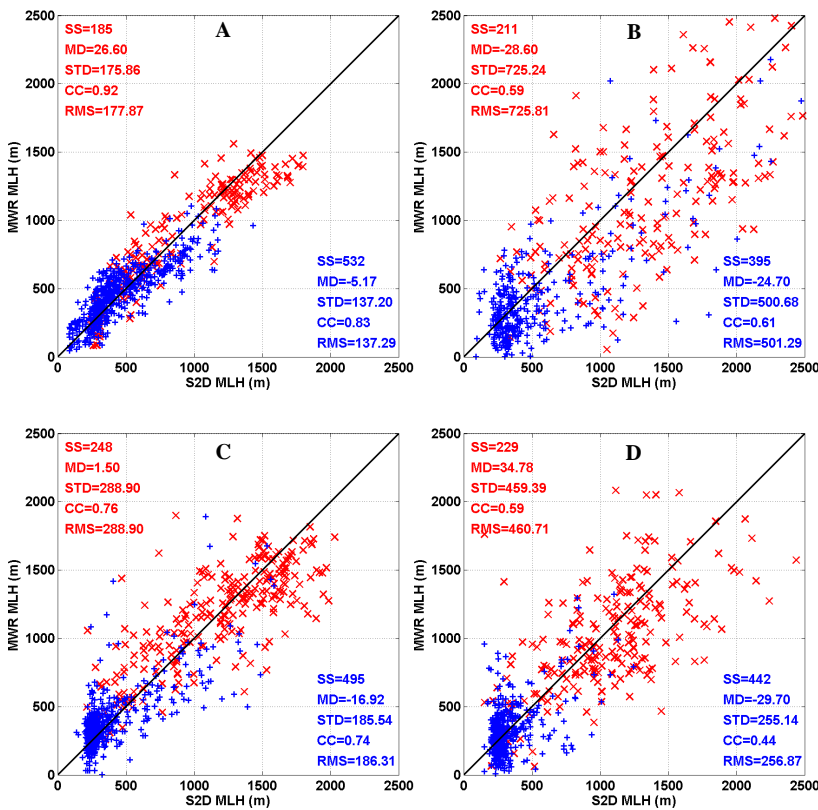

Fig. 5. Scatter plots of 1-hour average MLH (ma.g.1.) estimated from MWR ( $y$ axis) and lidar ( $x$ axis) observations during day (red) and night (blue). Each panel reports the sample size (SS), the mean difference (MD), the standard deviation (STD), the root mean square (RMS), and the correlation coefficient (CC). The diagonal $1: 1$ bisector line is also shown (black bold). The four panels indicate March (A), July (B), August (C), and September (D) 2011.

data for MLH during daytime only, and ceilometer data for nighttime MLH estimates. Figure 4 shows four shorter time series extending for 2-4 days, together with the MLH estimated from radiosondes with both the PTU and Rbn methods. Few diurnal cycles are shown, and the MWR estimates seem able to follow the lidar estimates during the morning and evening transitions. Note that different weather conditions are depicted in Fig. 4. In particular, low wind and fog were observed at the SIRTA site for most of the first three days of March. The global downwelling shortwave flux at surface remained below $300 \mathrm{~W} \mathrm{~m}^{-2}$, inhibiting the development of a convective boundary layer and causing low MLH values during both day- and nighttime. Strong (up to $10 \mathrm{~m} \mathrm{~s}^{-1}$ ) northwesterly wind with localized rainfall developed in the afternoon of 4 March, leading to MLH depression. Conversely, the two days between the end of May and the beginning of June were characterized by clear sky and scattered high clouds with moderate to low wind. The global downwelling shortwave flux at surface reached $1000 \mathrm{~W} \mathrm{~m}^{-2}$, causing a well-developed convective boundary layer between 10:00 and 19:00 UTC. The above two extreme situations are confirmed by the MLH estimated from radiosondes (both PTU and Rbn methods), though just twice a day ( $\sim 11: 00$ and 23:00 UTC). Mixed situations are found in the other cases in Fig. 4. In mid-July, low wind and intermittent cloudiness are registered. Broken clouds are present in the afternoon of
Table 2. Statistics for the comparison between $1 \mathrm{~h}$ average MLH estimated by MWR and lidar observations. The sample size (SS), the mean difference (MD), the standard deviation (STD), the root mean square (RMS), and the correlation coefficient (CC) are reported.

\begin{tabular}{lrrrrr}
\hline Period & $\begin{array}{r}\text { Sample } \\
\text { Size }\end{array}$ & $\begin{array}{r}\text { MD } \\
(\mathrm{m})\end{array}$ & $\begin{array}{r}\text { STD } \\
(\mathrm{m})\end{array}$ & $\begin{array}{r}\text { RMS } \\
(\mathrm{m})\end{array}$ & $\mathrm{CC}$ \\
\hline March & 718 & -0.76 & 166.57 & 166.57 & 0.90 \\
May & 105 & -86.09 & 944.35 & 948.35 & 0.42 \\
June & 289 & 84.93 & 761.13 & 765.87 & 0.53 \\
July & 606 & -26.06 & 588.07 & 588.65 & 0.68 \\
August & 743 & -10.77 & 225.34 & 225.59 & 0.89 \\
September & 671 & -7.69 & 340.00 & 340.08 & 0.77 \\
October & 507 & 6.99 & 381.77 & 381.83 & 0.52 \\
All data & 3653 & -3.64 & 435.75 & 435.76 & 0.69 \\
Bulk Train. & 3653 & -23.70 & 668.50 & 668.90 & 0.54 \\
\hline
\end{tabular}

20 July, and MLH is generally low apart from the afternoon of 19 July. The last time series (mid-October) shows a case in which the MWR-based MLH estimate is lower than the lidar estimate and also it is evidently closer to the radiosonde $\mathrm{Rbn}$ estimate (at Julian day 293.0, i.e. 20 October 00:00 UTC). Here, MWR and Rbn estimates are below $100 \mathrm{~m}$, while lidar and PTU are above $300-350 \mathrm{~m}$. This difference is important for air quality purposes as the shallower is MLH, the higher the threat of dispersed pollutants. In such a case, assuming a plume generated by a $100 \mathrm{~m}$-tall chimney, the different MLH values may lead either to lofting or fanning of the plume (Stull, 1988). This demonstrates that the proposed algorithm, establishing a linear relationship between $\mathrm{Tb}$ and MLH, is able to go beyond the information provided by the reference lidar estimates to reach values below the lidar overlap limit. This feature is probably due to the relatively high information content of MWR data on temperature profile in the lower few hundred meters. As can be seen in Fig. 3, this situation happens quite often in July-September. These results demonstrate the potential of the MWR-based method, confirming useful complementary information with respect to lidar on shallow boundary layer, which is to date a challenging task for ground-based measurements.

The agreement between MWR- and lidar-based MLH estimates is further quantified in Fig. 5 via correlation analyses. Here we show the scatter plots of MLH estimates for the four 1-month periods in Fig. 3, divided into daytime and nighttime observations. Each point corresponds to a $1 \mathrm{~h}$ average, to reduce the effects of temporal and spatial collocation of the two instruments (less than five meters apart). As one would expect, night- and daytime MLH estimates tend to distribute along the lower and higher values, respectively. The scatter plots confirm that the MWR-based estimate is able to follow the dynamical range spanned by the lidar-based $\mathrm{MLH}$, at least up to $2500 \mathrm{~m}$. Note also that low MLH values tend to form a cluster around $200-250 \mathrm{~m}$, close to the 


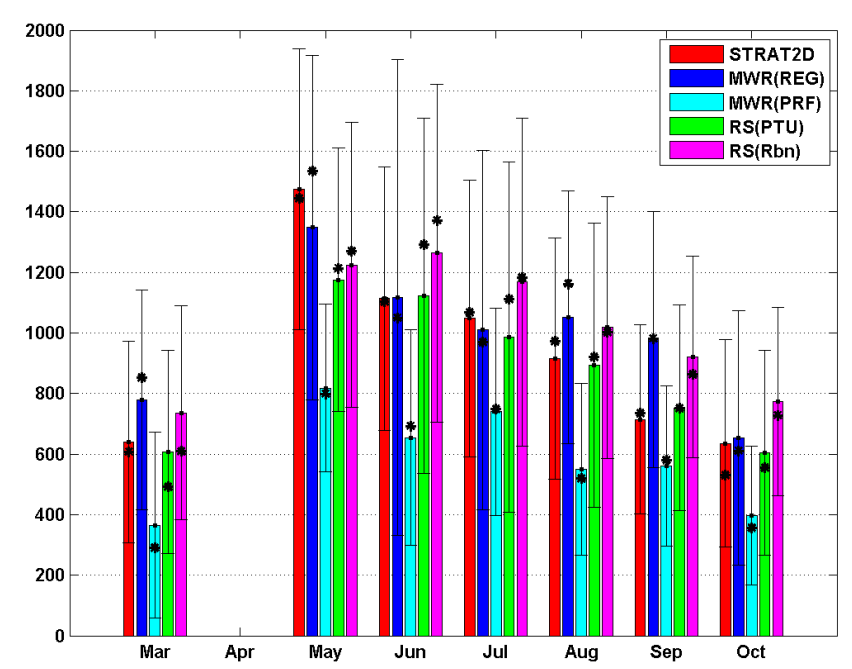

Fig. 6. Monthly mean average of diurnal MLH (m a.g.1.) as estimated by STRAT2D (red), MWR Tb regression (blue), MWR profiles (cyan), radiosonde PTU (green), and radiosonde Rbn (magenta). Black stars and error bars indicate the median value and one standard deviation, respectively. Values are taken as $1 \mathrm{~h}$ average around 11:30 UTC.

lidar overlap limit. The overall (i.e. day and night) statistical scores of the MWR- vs. lidar-based MLH comparison are summarized in Table 2 for each month. For the considered months, the availability of the MLH estimates range from 70 to $99 \%$ except for May and June (15 and $40 \%$, respectively), due to the instrumental problems of the lidar system. Indeed, the most significant discrepancies correspond to these two months, most probably due to relatively poor sample size and the associated low statistical confidence. Overall, the mean difference is generally small (within $10 \mathrm{~m}$ ), although it reaches significant values for May-June (up to $86 \mathrm{~m}$ ). As a consequence, standard deviation (STD) and RMS of the differences are almost indistinguishable, ranging from $166 \mathrm{~m}$ (March) to nearly $950 \mathrm{~m}$ (May). Note that the scatter is at minimum for March, likely due to the double temporal resolution of the original time series $(5 \mathrm{~min}$ instead of $10 \mathrm{~min}$ bins), causing a scatter reduction by a factor of 1.41 . The correlation coefficient between the MWR- and lidar-based estimate ranges from 0.42 in May to 0.90 in March. Considering the entire data set (3653 $1 \mathrm{~h}$ average bins), MD is $4 \mathrm{~m}$, RMS $436 \mathrm{~m}$, and correlation coefficient 0.69. However, if we take the results for the three months (March, August, September) in which we have more than $90 \%$ availability, the MD is within $10 \mathrm{~m}$, the RMS within $340 \mathrm{~m}$, and the correlation coefficient higher than 0.77 . Finally, using a unique bulk training from all months (i.e. semiannual), the performances degrade to $\mathrm{MD}=-24 \mathrm{~m}, \mathrm{RMS}=668.9 \mathrm{~m}$ and correlation coefficient 0.54 .

Since clouds do affect microwave observations at the considered channels, it is interesting to investigate the performances in clear and cloudy conditions. Thus, we divided

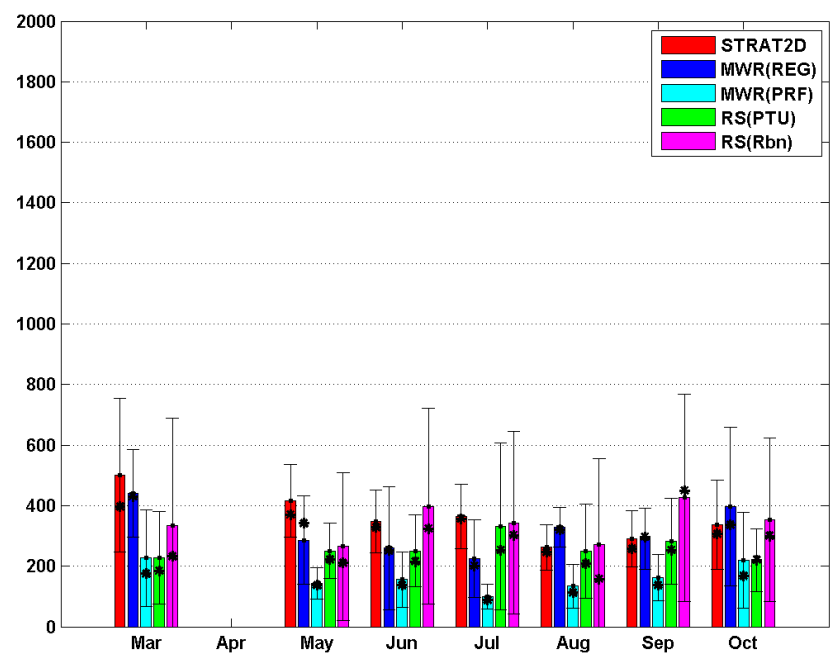

Fig. 7. As in Fig. 6 but for nocturnal MLH (m a.g.1.). Values are taken as $1 \mathrm{~h}$ average around 23:30 UTC.

our data set into clear and cloudy periods using the LWP measured by the MWR. We assume clear sky if the retrieved LWP is less than $20 \mathrm{~g} \mathrm{~m}^{-2}$, this value being a typical MWR uncertainty for LWP estimates (Westwater, 1993). As one may expect, the performances for MLH estimates turn out to be better in clear sky than in cloudy conditions (by 30\% in RMS and $24 \%$ in CC). We also tested a different approach, making a clear/cloudy (instead of day/night) separation of the training set. With respect to the results in Table 2, the performances degrade only slightly (3\% in RMS and $4 \%$ in CC), showing that a clear/cloudy separation may be as meaningful as the day/night separation we adopted.

In addition to the diurnal cycle, also the seasonal variability of the MLH is important for many applications like the parameterization of numerical weather prediction, climate, and air quality models. The seasonal variability of the MLH depends on a variety of factors, including mesoscale and synoptic forcings, location, and topography of the site under analysis. Figure 6 shows the comparison of diurnal monthly mean MLH as derived from different sources (lidar, MWR Tb, MWR profiles, and radiosondes). The diurnal values are computed by averaging all the data falling into a $1 \mathrm{~h}$ window from the launch time of daytime radiosonde (around 11:30 UTC). Values from both radiosonde methods (PTU and Rbn) are shown, with the PTU consistently lower than Rbn by 100-200 m. Overall, monthly mean MLH from MWR, lidar and radiosonde agree reasonably well (within $200 \mathrm{~m}$ ) and show a consistent seasonal variability, peaking in June at $\sim 1200-1400 \mathrm{~m}$ and decreasing down to $\sim 600 \mathrm{~m}$ in October. The MLH from MWR profiles is consistently lower than every other estimate by $300-600 \mathrm{~m}$, showing a reduced dynamical range for seasonal variability (from $800 \mathrm{~m}$ in June down to $450 \mathrm{~m}$ in October). Note that the estimates from MWR profiles are obtained with exactly 
the same method used for the radiosonde estimates (i.e. a combination of parcel, surface-based inversion, and potential temperature gradient methods). Thus, the differences between these two estimates we see in Fig. 6 are mainly related to the different sensitivity and vertical resolution provided by radiosonde and MWR profiles. Conversely, let us recall that the proposed method relies on a different approach, i.e. MLH estimates from direct MWR Tb observations. However, part of the differences in Fig. 6 shall be attributed to different temporal and spatial sampling of radiosonde and remote sensing instruments.

The nocturnal monthly mean MLH from the same sources as above is shown in Fig. 7. The nocturnal values are computed by averaging all the data falling into a $1 \mathrm{~h}$ window from the launch time of nighttime radiosonde (around 23:30 UTC). The nocturnal monthly mean MLH is significantly lower than diurnal, all the sources indicating values below $500 \mathrm{~m}$ and showing no clear seasonal signature. As for the diurnal MLH, the radiosonde PTU is consistently lower than Rbn, though the difference during night is reduced to $10-100 \mathrm{~m}$, while the MLH from MWR profiles is consistently lower than every other estimate by up to $150 \mathrm{~m}$. Nocturnal monthly mean MLH from radiosonde Rbn, lidar, and MWR Tb agree within 100-200 m

\section{Summary and conclusions}

This paper demonstrates the potential for estimating MLH directly from MWR Tb observations. The proposed approach is based on a multivariate linear regression trained with an a priori set of nearly colocated and simultaneous MWR Tb observations (multifrequency, multi-angle) and MLH estimates from a state-of-the-art lidar-based method aided by variance and stability index analysis. This approach is an alternative to the MLH estimates from MWR retrieved profiles, which have been used in recent intercomparison studies (Wang et al., 2012; Granados-Muñoz et al., 2012; Pratz, 2013), as it exploits the whole vertical information content provided by the MWR for the retrieval of the scalar quantity MLH. It may be argued that the proposed method needs an a priori set of reference data for training the algorithm, but this is indeed true also for MWR profile retrievals. In fact, the proposed approach could be easily implemented in addition to the implementation of temperature, humidity, IWV, and LWP retrievals, taking the radiosondes as reference. However, this is yet to be demonstrated, as the training may suffer from the rather incomplete coverage of the diurnal cycle provided by operational radiosonde launches.

The results show that the MWR-based MLH estimate is able to follow both the diurnal cycle and the day-to-day variability suggested by the lidar-based estimates. Our results also demonstrate that the proposed MWR-based method, although trained with lidar estimates, is able to detect low MLH values that are below the lidar overlap limit $(\sim 200 \mathrm{~m})$ prevailing during mainly stable boundary layer regimes at night. Comparison between MWR- and reference lidar-based MLH retrievals for a 7-month period (divided into $1 \mathrm{~h}$ average bins) shows a small mean difference $(4 \mathrm{~m})$, RMS equal to $436 \mathrm{~m}$, and correlation coefficient to 0.69 . However, taking into account the results for the three selected months (March, August, September) with more than $90 \%$ data availability, the mean difference is within $10 \mathrm{~m}$, the RMS within $340 \mathrm{~m}$, and the correlation coefficient higher than 0.77. Performances were shown to be better in clear sky than in cloudy conditions (30\% smaller RMS and $24 \%$ higher correlation).

The analysis of monthly mean MLH showed that during daytime MWR, lidar, and radiosonde Rbn agree within $200 \mathrm{~m}$. Although the available data set is not climatologically significant, as it covers less than one full year, the above estimates show a consistent seasonal variability, peaking in June at $\sim 1200-1400 \mathrm{~m}$ and decreasing down to $\sim 600 \mathrm{~m}$ in October. Estimates from MWR profiles are consistently lower than every other estimate by $300-600 \mathrm{~m}$, showing reduced seasonal variability. During nighttime, monthly mean MLH is below $500 \mathrm{~m}$, showing no clear seasonal signature. Estimates from MWR Tb and lidar agree within $200 \mathrm{~m}$ with radiosonde Rbn, while estimates from MWR profiles are consistently lower by $150 \mathrm{~m}$. Thus, when compared to MLH estimated from MWR profiles, the proposed method provide results that are more consistent with radiosonde Rbn estimates during both day and night. MLH monthly mean values from the proposed method agree well within one sigma with radiosonde Rbn estimates at 11:00 and 23:00 UTC, while MLH estimates from MWR retrievals are consistently lower by $\sim 300-500 \mathrm{~m}$ during daytime and $\sim 100-200 \mathrm{~m}$ during nighttime. Finally, this analysis concurs that the combination of MWR and lidar, as well as other remote and in situ sensing instrumentations, seems crucial for studying the temporal variability in MLH (both diurnal and seasonal). A synergetic approach, considering different techniques based on different aspects of the boundary layer, shall be explored to improve the MLH estimate during all stability conditions using further longer-term measurements at SIRTA atmospheric observatory.

Acknowledgements. Part of this work has been stimulated through the EU COST Action ES0702 EG-CLIMET. The authors would like to acknowledge the EU FP7 ACTRIS Infrastructure Project for providing support for measurements performed at the SIRTA observatory. SIRTA staff members are acknowledged for their support with instrument operation and maintenance. The two anonymous reviewers are acknowledged for their thoughtful suggestions.

Edited by: A. Macke 


\section{References}

Baars, H., Ansmann, A., Engelmann, R., and Althausen, D.: Continuous monitoring of the boundary-layer top with lidar, Atmos. Chem. Phys., 8, 7281-7296, doi:10.5194/acp-8-7281-2008, 2008.

Beyrich, F.: Mixing-height estimation in the convective boundary layer using sodar data, Boundary-Lay. Meteorol., 74, 1-18, 1995.

Bianco, L. and Wilczak, J. M.: Convective boundary layer depth: Improved measurement by doppler radar wind profiler using fuzzy logic methods, J. Atmos. Ocean. Technol., 19, 1745-1758, 2002.

Bianco, L., Wilczak, J., and White, A. B.: Convective boundary layer depth estimation from wind profilers: Statistical comparison between an automated algorithm and expert estimations, J. Atmos. Ocean. Technol., 25, 1397-1413, 2008.

Cimini, D., Hewison, T. J., Martin, L., Güldner, J., Gaffard, C., and Marzano, F.: Temperature and humidity profile retrievals from groundbased microwave radiometers during TUC, Meteorol. Z., 15, 45-56, 2006.

Cimini, D., Westwater, E. R., and Gasiewski, A. J.: Temperature and humidity profiling in the Arctic using millimeter-wave radiometry and 1DVAR, IEEE Trans. Geosci. Remote Sens., 48, 1381-1388, doi:10.1109/TGRS.2009.2030500, 2009.

Deardorff, J. W.: Parametrerization of the Planetary Boundary Layer for Use in General Circulation Models, Mon. Weather Rev., 100, 93-106, 1972.

Garratt, J. R.: The atmospheric boundary layer, Cambridge University Press, Cambridge, ISBN:0521380529, 1992.

Granados-Muñoz, M. J., Navas-Guzmán, F., Bravo-Aranda, J. A., Guerrero-Rascado, J. L., Lyamani, H., Fernández-Gálvez, J., and Alados-Arboledas, L.: Automatic determination of the planetary boundary layer height using lidar: One-year analysis over southeastern Spain, J. Geophys. Res., 117, D18208, doi:10.1029/2012JD017524, 2012.

Haeffelin, M., Barthès, L., Bock, O., Boitel, C., Bony, S., Bouniol, D., Chepfer, H., Chiriaco, M., Cuesta, J., Delanoë, J., Drobinski, P., Dufresne, J.-L., Flamant, C., Grall, M., Hodzic, A., Hourdin, F., Lapouge, F., Lemaître, Y., Mathieu, A., Morille, Y., Naud, C., Noël, V., O'Hirok, W., Pelon, J., Pietras, C., Protat, A., Romand, B., Scialom, G., and Vautard, R.: SIRTA, a ground-based atmospheric observatory for cloud and aerosol research, Ann. Geophys., 23, 253-275, doi:10.5194/angeo-23-253-2005, 2005.

Haeffelin, M., Angelini, F., Morille, Y., Martucci, G., Frey, S., Gobbi, G. P., Lolli, S., O’Dowd, C. D., Sauvage, L., XuerefRémy, I., Wastine, B., and Feist, D. G.: Evaluation of MixingHeight Retrievals from Automatic Profiling Lidars and Ceilometers in View of Future Integrated Networks in Europe, BoundaryLay. Meteorol., 143, 49-75, doi:10.1007/s10546-011-9643-z, 2012.

Holzworth, G. C.: Estimates of mean maximum mixing depths in the contiguous United States, Mon. Weather Rev., 92, 235-242, 1964.

Löhnert, U. and Maier, O.: Operational profiling of temperature using ground-based microwave radiometry at Payerne: prospects and challenges, Atmos. Meas. Tech., 5, 1121-1134, doi:10.5194/amt-5-1121-2012, 2012.
Löhnert, U., Turner, D., and Crewell, S.: Ground-Based Temperature and Humidity Profiling Using Spectral Infrared and Microwave Observations. Part I: Simulated Retrieval Performance in Clear-Sky Conditions, J. Appl. Meteorol. Climatol., 48, 10171032, 2009.

Lolli, S., Sauvage, L., Stachlewska, I., and Coulter, R.: Assessment of the EZ LIDAR and Micro Pulse Lidar (MPL) performances at ARM Southern Great Plains (SGP) Central Facility for the measurement of clouds and aerosols, Geophys. Res. Abstracts, 10, EGU2008-A-11091, 2008.

Lolli, S., Sauvage, L., Loaec, S., and Lardier, M.: EZ Lidar: a new compact autonomous eye-safe scanning aerosol Lidar for extinction measurements and PBL height detection. Validation of the performances against other instruments and intercomparison campaigns, Óptica Pura y Aplicada, 44, 33-41, 2011.

Menut, L., Flamant, C., Pelon, J., and Flamant, P. H.: Urban boundary-layer height determination from lidar measurements over the Paris area, Appl. Opt., 38, 945-954, 1999.

Pal, S., Behrendt, A., and Wulfmeyer, V.: Elastic-backscatter-lidarbased characterization of the convective boundary layer and investigation of related statistics, Ann. Geophys., 28, 825-847, doi:10.5194/angeo-28-825-2010, 2010.

Pal, S., Xueref-Remy, I., Ammoura, L., Chazette, P., Gibert, F., Royer, P., Dieudonné, E., Dupont, J.-C., Haeffelin, M., Lac, C., Lopez, M., Morille, Y., and Ravettad, F.: Spatio-temporal variability of the atmospheric boundary layer depth over the Paris agglomeration: An assessment of the impact of the urban heat island intensity, Atmos. Environ., 63, 261-275, 2012.

Pal, S., Haeffelin, M., and Batchvarova, E.: Exploring a geophysical process-based attribution technique for the determination of the atmospheric boundary layer depth using aerosol lidar and near surface meteorological measurements, J. Geophys. Res.-Atmos., 118, 9277-9295, doi:10.1002/jgrd.50710, 2013.

Piringer, M., Joffre, S., Baklanov, A., Christen, A., Deserti, M., Ridder, K., Emeis, S., Mestayer, P., Tombrou, M., Middleton, D., Baumann-Stanzer, K., Dandou, A., Karppinen, A., and Burzynski, J.: The surface energy balance and the mixing height in urban areas - activities and recommendations of COST-Action 715, Boundary-Lay. Meteorol., 124, 3-24, 2007.

Praz, C.: Automatic planetary boundary layer detection: validation of various detection instruments and methods, comparison with the forecast model Cosmo-2 and one-year climatology, MeteoSwiss-EPFL Internship Report, January, 2013.

Rose, Th. and Czekala, H.: RPG's Atmospheric Remote Sensing Radiometers - Operating Manual, Version 8.12, August, 2010.

Rose, T., Crewell, S., Löhnert, U., and Simmer, C.: A network suitable microwave radiometer for operational monitoring of the cloudy atmosphere, Atmos. Res., 75, 183-200, 2005.

Royer, P., Chazette, P., Sartelet, K., Zhang, Q. J., Beekmann, M., and Raut, J.-C.: Comparison of lidar-derived PM10 with regional modeling and ground-based observations in the frame of MEGAPOLI experiment, Atmos. Chem. Phys., 11, 1070510726, doi:10.5194/acp-11-10705-2011, 2011.

Schmid, P. and Niyogi, D.: A Method for Estimating Planetary Boundary Layer Heights and Its Application over the ARM Southern Great Plains Site, J. Atmos. Ocean. Technol., 29, 316322, doi:10.1175/JTECH-D-11-00118.1, 2012. 
Seibert, P., Beyrich, F., Gryning, S. E., Joffre, S., Rasmussen, A., and Tercier, P.: Review and intercomparison of operational methods for the determination of the mixing height, Atmos. Environ., 34, 1001-1027, 2000.

Seidel, D. J., Ao, C. O., and Li, K.: Estimating climatological planetary boundary layer heights from radiosonde observations: Comparison of methods and uncertainty analysis, J. Geophys. Res., 115, D16113, doi:10.1029/2009JD013680, 2010.

Solheim, F., Godwin, J., Westwater, E., Han, Y., Keihm, S., Marsh, K., and Ware, R.: Radiometric profiling of temperature, water vapor, and cloud liquid water using various inversion methods, Rad. Sci., 33, 393-404, 1998.

Sørensen, J. H., Rasmussen, A., and Svensmark, H.: Forecast of Atmospheric Boundary-Layer Height Utilised for ETEX RealTime Dispersion Modelling. Phys. Chem. Earth, 21, 435-439, 1996.

Steeneveld, G. J., van de Wiel, B. J. H., and Holtslag, A. A. M.: Diagnostic equations for the stable boundary layer height: Evaluation and dimensional analysis, J. Appl. Meteor. Climatol., 46, 212-225, 2007.

Stull, R. B.: An introduction to boundary layer meteorology, Kluwer Academic Publishers, Dordrecht/Boston/London, ISBN 9027727686, 1988.
Vickers, D. and Mahrt, L.: Evaluating formulations of stable boundary layer height, J. Appl. Meteor., 43, 1736-1749, 2004.

Vogelezang, D. H. P. and Holtslag, A. A. M.: Evaluation and model impacts of alternative boundary-layer height formulations, Boundary-Lay. Meteorol., 81, 245-269, 1996.

von Engeln, A. and Teixeira, J.: A Planetary Boundary Layer Height Climatology derived from ECMWF Re-analysis Data, J. Climate, 26, 6575-6590, doi:10.1175/JCLI-D-12-00385.1, 2013.

Wang, Z., Cao, X., Zhang, L., Notholt, J., Zhou, B., Liu, R., and Zhang, B.: Lidar measurement of planetary boundary layer height and comparison with microwave profiling radiometer observation, Atmos. Meas. Tech., 5, 1965-1972, doi:10.5194/amt5-1965-2012, 2012.

Westwater, E. R.: Ground based microwave remote sensing of meteorological variables, in: Atmospheric Remote Sensing by Microwave Radiometry, edited by: Janssen, M., 145-213, John Wiley, New York, 1993.

Wetzel, P. J.: Toward parameterization of the stable boundary layer, J. Appl. Meteorol., 21, 7-13, 1982. 